\title{
Credit Availability and Technical Efficiency of Boro Rice in Pabna District, Bangladesh: A Stochastic Frontier Analysis
}

\author{
Md. Zuel Rana*, Md. Yahia Bapari \\ Department of Economics, Pabna University of Science and Technology, Pabna, Bangladesh \\ Email address: \\ zuel.110819@gmail.com(Md.Z.Rana),md.yahiabapari@yahoo.com(Md. Y. Bapari) \\ ${ }^{*}$ Corresponding author
}

To cite this article:

Md. Zuel Rana, Md. Yahia Bapari. Credit Availability and Technical Efficiency of Boro Rice in Pabna District, Bangladesh: A Stochastic Frontier Analysis. International Journal of Sustainable Development Research. Vol. 4, No. 1, 2018, pp. 8-16.

doi: $10.11648 /$ j.jijsdr.20180401.12

Received: December 31, 2017; Accepted: January 29, 2018; Published: May 30, 2018

\begin{abstract}
The goal of this study is to analyze the technical efficiency and its determinants of rice production in Bangladesh using data from Boro rice farmers of Pabna district. Required data are collected from 100 Boro rice producing farmers of Pabna district selected using multistage random sampling procedure. In scrutinizing the data, farm specific technical efficiency scores are estimated using the Cobb-Douglas Stochastic Frontier Production function approach. The study found that technical efficiency of Boro rice farms in Pabna district are 92.3\% which indicate that Boro rice farms have been operating below the maximum level of production frontier. It is also found that 'ploughing cost' 'pesticide cost', 'labor cost', and 'irrigation' are the significant elements that affect the level of technical efficiency while "fertilizer cost' and 'seed' are found insignificant in moving technical efficiency of Boro rice production in the study area. Farmers can increase their production of Boro rice by $7.7 \%$ given the available technology through increasing the use of labor, seed also irrigation inputs and also by using proper amounts of fertilizer and pesticide inputs. The outcomes from the assessed inefficiency effect model make known that farm size, age, education, training and credit facility are the significant influences which are negatively related to technical inefficiency of Boro rice production. This study provides that steps to raise education, training as well as credit facilities are influential to reduce technical inefficiency of rice production in the study area. Intuitively, in this connection as a long run approach, the investment on research connected activities should be increased to change the production technology.
\end{abstract}

Keywords: Technical Efficiency, Credit Availability, Stochastic Frontier Approach, Rice Production, Efficiency Index, Inefficiency Factors, Bangladesh

\section{Introduction}

Bangladesh's economy is dominated by agriculture, which continues to play a very important role in creating job opportunities, supplying raw materials to industries, obtaining foreign currency and achieving food security. Among the four basic agricultural sub-sectors, crops are one of these and rice, in particular Boro rice, has been treated as a mainstream of this sub-sector. Boro rice is growing by leaps and bounds in Bangladesh. Boro rice production is appreciated during the dry season because it is expected that the increasing use of irrigation in the country will increase the production of Boro rice to achieve food self-sufficiency. The agricultural sector contributes about 16 percent of gross domestic product (GDP) and employs over 45 percent of the total workforce (Bangladesh Bureau of Statistics (BBS), 2015). The agricultural sector plays an important role in the economic development and food security of this highly populous country. Historically, the agricultural sector has been prominent for a long time in Bangladesh. In Bangladesh, $88.44 \%$ of all households are in rural areas and very dependent on agriculture to live (Bangladesh agricultural census, 2008). Agriculture provides the basic food for survival of subsistence farmers in Bangladesh. The subsistence farmers' account represents the largest percentage of people engaged in agriculture. Bangladesh 
Agriculture already works at its land border and there is little or no space to expand the arable land to meet the growing demand for food for its growing population (Rahman, 2003). In addition, high population growth, frequent crop losses following floods or drought exert pressure to intensify land use. Therefore, this country simply cannot afford any decrease in the productivity of its limited arable land of 8.44 million hectares (BBS, 2006). It must also maintain optimal productivity of our existing arable land to achieve higher yields. In Bangladesh, the agricultural sector is dominated by the sub-sector of the crop and the sub-sector of the crop is led by the production of rice. Rice is the cultivation of basic foods and is grown extensively in all seasons of the year. However, in Bangladesh, rice is grown in three diverse seasons: Boro (rice monsoon) from January to June, Aus (pre monsoon rice) from April to August and Aman (monsoon rice) from August to December. Area under rice cultivation of total cultivated area in Bangladesh was 28124 thousand acre of which both local variety and HYV Aus rice cultivated was 2516 thousand acre, Aman was 13341 thousand acre and Boro was 11794 thousand acre in fiscal year 2015- 2016. The total production of rice was 34710 thousand M. Tons of which Aus was 2288 thousand M. Tons, Aman was 13448 thousand M. Tons and Boro 18938 thousand M. Tons while in 2015-16 (BBS-2016). The Pabna district is predominantly based on agriculture. Rice is produced to a large extent at the same time as other minor crops, such as wheat, potatoes, oilseeds, corn, vegetables, fruit and spices. Agriculture is the main occupation of the majority of the population and its livelihood depends almost entirely on agricultural activities. They also have little chance of complementary employment during the growth seasons. All these characteristics confirm the typical characteristics of Bangladesh agriculture. Previous studies on Bangladesh (Wadud and White, 2000; Rahman, 2002;) have focused mainly on technical or economic efficiency, with the exception of Coelli et al. (2002). As Coelli et al. (2002), this study applies data envelope analysis (DEA), so it is not necessary to assume a simplistic functional form. However, measuring production efficiency in agricultural production is an important issue from the point of view of agricultural development, as it provides relevant information useful for making sound management decisions, allocating resources and formulating agricultural policies and institutional improvements.

\section{Review of the Literature}

There are very few studies conducted in Bangladesh that have measured the technical efficiency of Boro rice and its determinants as credit availability. Hasan. M et al., (2016) conducted a survey that used the Cobb-Douglas stochastic production frontier to estimate the technical efficiency of the Boro rice fields and an inefficiency effect model to determine the elements affecting the level inefficiency of Boro Rice Farms. The empirical outcomes of the Cobb-Douglas stochastic production approach display that the technical efficiency of the Boro rice production is on average 0.92.
Hasnain M. Nehal, et al. (2015) conducted a study of 115 selected Meherpur district boro rice farmers using the multistage random sampling procedure. In analyzing the data, the specific technical efficiency scores of each farm are estimated using the Translog Stochastic Frontier Production approach. The study found that the technical efficiency of boro rice fields in the Meherpur district is $89.5 \%$. It has also been found that "work", "fertilizer and pesticide", "seed" and "irrigation" are the important factors affecting the level of technical efficiency, while the "size of the company" and the "cost of plowing" it is considered insignificant to influence the technical efficiency of the production of boro rice in the study area Hossain. M et al. (2012) have shown that the mean technical efficiency of rice crops in the Naogaon district of Bangladesh is 0.80 , and in this case technical inefficiency is negatively affected by factors such as age and education, agricultural experience and agricultural policy. Khan et al. (2010) studied the technical efficiency of a sample of 150 rice farmers in Bangladesh. The production boundaries of Cobb-Douglas have been estimated for the producers of Boro and Amon rice. The average technical efficiency scores reported were $95 \%$ and $91 \%$, respectively, and the result indicated that farmers' education had a significant influence on the technical efficiency of the Boro rice producers. Rahman and Rahman (2009) examined how land fragmentation and ownership of resources (land, animal energy, and family work) have influenced the productivity and technical efficiency of rice farmers in Bangladesh, using data from agricultural surveys. They estimated that the average technical efficiency was $91 \%$ and that the efficiency differentials were markedly influenced by the fragmentation of the land and the property of the resources. Asadullah and Rahman (2009) examined the influence of education on the efficiency of agricultural production for a wide range of data obtained from 141 villages and their analyzes revealed that domestic education significantly reduces production inefficiencies. Wadud (2003) used both Data Envelopment Analysis (DEA) and Stochastic Frontier Approaches (SFA) to examine the technical, allocative and economic efficiency of a sample taken from 150 families of farmers and found a high level of technical efficiency. Technical efficiency has been described by land degradation and also irrigation infrastructure. Coelli et al. (2002) used the DEA and examined the technical, allocation, cost and scale efficiencies for modern Aman and modern Boro rice from a total of 406 sample families. They reported a technical efficiency of $66 \%$ for the Aman rice, while for the Boro rice a technical efficiency of $69 \%$ was found. Education, growth experience and farm size influenced the technical efficiency of HYO Boro rice and also education was positively related to technical efficiency (Sharif and Dar, 1996).

However, no studies have been carried out on technical efficiency at farm level and its determinants that focus on the financial factor through microfinance or credit availability. This study presented a new explanatory variable called credit availability that has not been examined in preceding studies as a possible determinant of efficiency in rice cultivation. 
Therefore, the study attempts to verify the hypothesis that access to agricultural credit affects the efficiency of rice production. In the present study, the researcher carefully selected the areas of study so that the actual results were representative.

\section{Methodology}

\subsection{Study Selection and Sample Areas}

The selection of the study area is an important step for the study of business management. Therefore, the present study was based on primary data collected specifically from the Pabna district of Bangladesh. Respondents' selections were made using the simple multistage random sampling procedure. At the first stage, two out of nine upazilas under Pabna district has been selected using simple random sampling. These upazilas are Atgharia Upazila and the other is Chatmohor Upazila. There are 5 and 11 unions under Atgharia Upazila and Chatmohor Upazila, respectively. At the second stage, using random sampling technique, from each upazila one union were chosen which is Laksmipur union of Atgharia upazila and Failjana union of Chatmohor Upazila. At the third stage, three villages under each union, on the basis of higher concentration of Boro rice production, three villages namely Folia, Islampur and Balughata of Lakshmipur Union under Atgharia Upazila and 3 villages namely Luxmipur, Dublapara and Idulpur of Failjana Union under Chatmohor Upazila has been selected for the study. Finally, a list of farmers of the selected villages were collected from the upazila agriculture office and chosen total of 100 respondents for data collection.

\subsection{Questionnaire for Data Collection}

For data collection, a well-organized questionnaire is required to achieve the required objective. Given the objectives of the study, the questionnaire was previously tested by interviewing some Boro rice growers, consequently, the necessary changes were made, the additions and the alternations and draft of the questionnaire then concluded. To meet the extreme needs of this study on the technical efficiency of the production of Boro rice, only primary data were collected. The final questionnaire contained three categories of information. The objective of the first category was to obtain information on the socio-economic conditions of selected farmers. The second category contained information on the costs and returns of the two selected crops. The third category of information was linked to the limits and problems that farmers face in producing Boro rice. For the present study, information was collected from the Boro rice producers through a field / face-to-face interview. The same researcher has compiled the relevant data of the rice producers selected by Boro. Before interviewing, the selected farmer has been contacted so that they can be interviewed according to their temporal convenience. At the time of the interview, the investigator questions systematically and explained the objectives of the study when deemed necessary.

\subsection{Method of Analysis}

Technical efficiency is the maximum possible result obtained from a given set of inputs. According to Farrell, M. J. (1957), within a given level of input and technology, the border production function can show the maximum possible performance of a company. Therefore, the present study uses the stochastic frontier production function to measure the technical efficiency of the Boro rice crop in the study area. To achieve a significant result and to achieve the main objectives of the study, the data were analyzed in the following analytical techniques.

\subsection{Theoretical Model for the Estimation of Technical Efficiency}

According to the Farrell model (1957), technical efficiency (ET) is defined as the ability of a farm to attain the best production of a given set of factors (oriented to the increase of production) or, alternatively, as the measure of the ability to use the minimum possible amount of input to produce a certain level of production (oriented towards saving input) (Greene, 1980; Atkinson and Cornwell, 1994). As a result, technical inefficiency is defined as the extent to which companies fail to achieve optimal production. Farrell (1957) proposed measuring the TE of a farm by comparing its observed production with production that could be produced from a fully efficient farm, given the same input package. Aigner et al. (1977), Meeusen and van den Broeck (1977) independently proposed the function of stochastic frontier production (SF) takings into account the presence of measurement errors and other noises in the data, which are beyond the control of the operators. Farmers in general operate under conditions of uncertainty and, therefore, the present study employs a stochastic production frontier approach to measure TE. Following Battese and Coelli (1995), the following stochastic model of border production and the model of inefficiency effects are estimated simultaneously using a single stage with the FRONTIER 4.1 software developed by Coelli (1996).

Following its specifications, this study specifies the general SF model defined as:

$$
Y i=f\left(X_{i} ; \beta\right)+\varepsilon_{i} i=1,2, \ldots . N
$$

Where, $Y_{i}$ is the output value of the Boro rice for the $i^{\text {th }}$ farm, $X_{i}$ is a vector of $k$ input (or cost of inputs), $\beta$ is a vector of unknown parameters to be estimated, $f($.) It is a form functional for the frontier (Cobb-Douglas, translog or quadratic), $\varepsilon_{\mathrm{i}}$ is an error term and $\mathrm{N}$ is the total number of observations. The stochastic frontier production is similarly called a "composite error" model because it postulates that the error term $\varepsilon_{\mathrm{i}}$ is divided into two components: a random stochastic error component (random shocks / white noise) and a defined technical component of inefficiency of the following the way:

$$
\varepsilon_{\mathrm{i}}=\mathrm{V}_{\mathrm{i}}-\mathrm{U}_{\mathrm{i}}
$$


Where, $\mathrm{V}_{\mathrm{i}}$ is a normally distributed bilateral random error that captures the stochastic effects outside the control of farmers (for example, weather conditions, natural disasters, omitted variables, luck, exogenous shocks, measurement errors and other statistical disturbances). It is identical, independently and normally distributed, $N\left(\begin{array}{ll}0 & \left.\sigma^{2} \mathrm{v}\right)\end{array}\right.$ independent of the user interface. Thus, $\mathrm{V}_{\mathrm{i}}$ allows the production limit to vary between farms or over time for the same farms and therefore the production limit is of a stochastic nature.

The term $U_{i}$ (non-negative asymmetric error term) is a one-sided efficiency component $\left(U_{i} \geq 0\right)$ that captures $i^{\text {th }}$ technical inefficiency. This can follow a normal, exponential, normal truncated or gamma distribution (Aigner et al., 1977; 1990; Meeusen and Broeck, 1977). In this study it hypothesized that $U_{i}$ follows the mean normal distribution symbolically $\mathrm{N}\left(0, \sigma^{2} u\right)$ as has been done in several studies published in the applied frontier stochastic literature. It is obtained by zero truncation of the normal distribution with mean $\mu$ and variance $\left(\sigma^{2} u\right)$. If $\mu$ is preassigned to zero, then the distribution is half normal. Furthermore, it is assumed that the two error components ( $\mathrm{V}$ and $\mathrm{U}$ ) are independent of one another.

Other vital parameters estimated in this analysis include the square sigma ratio $\left(\sigma^{2} s\right)$, gamma $(\gamma)$, and log-likelihood. The $\sigma^{2}$ s indicates the goodness of the adaptation of the model used, and gamma gives the proportion of the deviation of the production of Boro rice from the production limit caused by technical inefficiency. For example, if $\gamma=0$, indicates that the $U_{i}$ is absent in the model. If $\gamma=1$, it means that all deviations from the frontier are due to technical inefficiency. The Log Likelihood Report is used to evaluate the significant presence of technical inefficiency effects in farmers' production.

The variance parameters of the model are parameterized as:

$$
\sigma_{s}^{2}=\sigma_{v}^{2}+\sigma_{u}^{2}, \gamma=\sigma_{u}^{2} \div \sigma_{s}^{2} \text { So that } 0 \leq \gamma \leq 1
$$

Where, $\sigma_{s}^{2}=$ Variance parameters of the sample statistics $\sigma_{\mathrm{v}}^{2}=$ Variance of the error term due to noise $\sigma_{\mathrm{u}}^{2}=$ Variance of the error term resulting from technical inefficiency

The $\gamma$ parameter must be between 0 and 1 . Here, $\sigma^{2}{ }_{s}$ indicates the total variation in the dependent variable due to technical inefficiency $\left(\sigma_{\mathrm{u}}^{2}\right)$ and random shocks $\left(\sigma^{2}{ }_{\mathrm{v}}\right)$ together. The gamma $(\gamma)$ parameter explains the impact of inefficiency on production. The maximum likelihood estimate (MLE) of equation (1) provides coherent estimators for the parameters $\beta, \gamma$, and $\sigma^{2}$. Aigner et al. (1977) expressed the likelihood function in terms of the two variance parameters, $\sigma_{\mathrm{s}}^{2}=\sigma_{\mathrm{u}}^{2}+$ $\sigma_{\mathrm{v}}^{2}$ and $\gamma=\sigma_{\mathrm{u}} / \sigma_{\mathrm{v}}$. Battese and Colli (1977) have suggested that the parameter, $\gamma=\sigma_{\mathrm{u}}{ }^{2} / \sigma_{\mathrm{s}}{ }^{2}$, be used because it has a value between zero and 1 and this property allows to obtain an appropriate initial value for an iterative maximization process, while the parameter $\gamma$ it could be a non-negative value. A value of $\gamma$ closer to zero implies that much of the variation of the observed output of the boundary output is due to random stochastic effects, while a value of $\gamma$ closer to one implies a random variation ratio in the output explained by effects inefficiency or differences in technical efficiency.

The function determining the technical inefficiency outcome is defined in its general form as a linear function of socio economic in addition management factors:

$$
\mathrm{U}_{\mathrm{i}}=\mathrm{F}\left(\mathrm{Z}_{\mathrm{i}}\right)
$$

The more detail about dependent and independent variables is given in empirical model. According to Aigner et al., (1977), as cited by Ahmadu and Erhabor (2012), technical efficiency of the farmer is expressed below

$$
\mathrm{TE}_{\mathrm{i}}=\mathrm{Y}_{\mathrm{i}} / \mathrm{Y}_{\mathrm{i}}^{*}
$$

Where, $\mathrm{TE}_{\mathrm{i}}=$ Technical efficiency of the $\mathrm{i}^{\text {th }}$ farmer $\mathrm{Y}_{\mathrm{i}}=$ Observed output of the $i^{\text {th }}$ farmer $(\mathrm{kg}) \mathrm{Y}_{\mathrm{i}}{ }^{*}=$ Potential output $(\mathrm{kg})$. This is the technical efficiency (TE) which is defined as the ratio of observed production to maximum feasible production which is called frontier output. When $\mathrm{TE}=1$, it shows that a farmer obtains maximum feasible output, while if $\mathrm{TE}<1$ means a shortfall of the observed output to the frontier output.

\subsection{The Empirical Model}

The above log- linear form of Cobb-Douglas production function is used to estimate the effects of various inputs for the production of Boro rice. The independent variables Seed, labor, fertilizer, insecticide, and ploughing and irrigation costs has been taken into consideration which is likely to have impact on Boro rice production. All variables have been expressed in monetary terms. The model used in this study is defined by the following equation.

$$
\begin{gathered}
\ln Y_{i}=\beta_{0}+\beta_{1}\left(\ln X_{1}\right)+\beta_{2}\left(\ln X_{2}\right)+\beta_{3}\left(\ln X_{3}\right)+\beta_{4}\left(\ln X_{4)}+\beta_{5}\left(X_{5}\right)+\beta_{6}(\ln \right. \\
\left.X_{6}\right)+V_{i}-U_{i}
\end{gathered}
$$

Where, $\mathrm{Y}_{\mathrm{i}}=$ Total market value of the output of Boro rice/ of $i^{\text {th }}$ farm per bigha (Tk); Ln = Natural logarithm, $X_{1}=$ Seed cost per bigha (Tk), $\mathrm{X}_{2}=$ Ploughing cost per bigha (Tk), $\mathrm{X}_{3}=$ Insecticide cost per bigha (Tk), $X_{4}=$ Fertilizer cost per bigha (Tk), $X_{5}=$ Labor cost per bigha (Tk), $X_{6}=$ Irrigation cost per bigha (Tk), and $\mathrm{V}_{\mathrm{i}}=$ random variable associated with disturbances in production which captures the randomness outside the control of the farmers; $\mathrm{U}_{\mathrm{i}}=$ stochastic disturbance term that represents farm specific or socioeconomic characteristics related to production efficiency that captures randomness under the control of the farmers.

To identify the socioeconomic and farm level physical characteristics that contribute to inefficiency of the farms, the inefficiency effect model is constructed as follows.

$$
\begin{gathered}
\mathrm{Ui}=\delta 0+\delta 1 \mathrm{Z} 1+\delta 2 \mathrm{Z} 2+\delta 3 \mathrm{Z3}+\delta 4 \mathrm{Z} 4+\delta 5 \mathrm{Z5}+\delta 6 \mathrm{Z6}+ \\
+\delta 7 \mathrm{Z} 7+\delta 8 \mathrm{Z} 8+\delta 9 \mathrm{Z} 9+\omega \mathrm{i}
\end{gathered}
$$

Where, $\mathrm{U}_{\mathrm{i}}=$ represents the inefficiency that is related to different exogenous or farm specific socioeconomic factors of Boro rice production; $\delta$ 's $=$ are unknown parameters to be estimated; $Z_{1}=$ Total farm size (bigha); $Z_{2}=$ Household size (number of member); $Z_{3}=$ Age of the household head (year); $\mathrm{Z}_{4}=$ Education (year of schooling); $\mathrm{Z}_{5}=$ Experience of the 
farmer (year); $Z_{6}=$ Training (dummy, $1=$ yes, no $=0$ ); $Z_{7}=$ Land fragmentation (no. of plots cultivated by the farmer) $Z_{8}$ $=$ Extension services (dummy, $1=$ yes, no $=0) ; Z_{9}=$ Credit facility (dummy, $1=$ yes, no $=0) ; \omega_{\mathrm{i}}=$ stochastic disturbance term. The model will be estimated by maximum likelihood estimation (MLE) technique available in the computer program called FRONTIER VERSION 4.1 developed by Coelli (1996). From this equation the researcher will derive technical efficiency and the values of input coefficients.

\section{Data Description}

In the present study, data on output and inputs are used to estimate farm level technical efficiency of Boro rice production. Before estimation, some properties of data such as mean, minimum and maximum are calculated. Farm output is defined as the total market value of produced Boro rice in 2016-17 production years. Labor cost comprises the total cost incurred by both family and also hired labor employed in the production. Fertilizer cost contains the cost of buying organic and inorganic fertilizers. The cost of irrigation is calculated as the total cost of irrigation for rice farms in the Boro season. Seed cost comprises the cost of using both local and better-quality varieties of seeds. Pesticide cost includes total cost of pesticide used in the production. Total ploughing cost is measured by the cost of ploughing the Boro plots by power-tiller and bullocks. The measurement of variables and the summary statistics of the explanatory variables used in the stochastic frontier model are shown in Table 1:

Table 1. Summary Statistics of the Variables Used in the Stochastic Frontier Model.

\begin{tabular}{|c|c|c|c|c|}
\hline \multicolumn{5}{|l|}{ Boro rice } \\
\hline Variables & Max. & Min. & Mean & Std. Deviation \\
\hline Output(Taka/bigha & 22235 & 12400 & 16478.40 & 2418.93226 \\
\hline Seed cost(Taka/bigha & 800 & 300 & 555.30 & 144.19022 \\
\hline Plough-ing Cost(Taka/bigha) & 1500 & 500 & 641 & 166.26922 \\
\hline Pesticide Cost(Taka/bigha) & 600 & 180 & 421.60 & 107.07988 \\
\hline Fertilizer Cost(Taka/bigha) & 1700 & 820 & 1216.26 & 167.60124 \\
\hline Irrigation Cost(Taka/bigha) & 6333.33 & 3800 & 5147.4167 & 710.76350 \\
\hline Gross Mergin(Taka/bigha) & 6600.88 & & & \\
\hline Benefit Cost ratio & 1.44 & & & \\
\hline
\end{tabular}

It is observed that the average farm output per bigha of Boro rice is 16478.40 with SD value of 2418.932 . There is wide variation in the yield rate across the farms and this leaves scope for further enhancing the productivity in the selected areas of Pabna district. The farmer produces an output of Boro rice is 16478.40 per bigha by putting, in an average, 555.30 of seed cost, 641 of ploughing cost, 421.60 of pesticide cost, 1216.26 of fertilizer cost, 4984 of labor cost and 5147.4167 of irrigation cost. The study finds that gross margin and benefit cost ratio are 6600.88 and 1.44 , respectively for Boro rice farmer and this shows higher profitability level than other crops in study areas.

There is no proper guideline in the literature as to which variables are to be included in the stochastic frontier production function and which in the technical inefficiency effects model. For example, Wilson et al. (1998) included, among others, the cultivated potato area in the production function and the proportion of the cultivated potato area that is irrigated in the technical inefficiency effects model. Coelli and Battese (1996) included land variable, among others, in the production function and land size, among other, in the technical inefficiency effects model. Parikh and Shah (1994) and Parikh et al. (1995) included off-farm work, farm assets, nonfarm assets and credit in the technical inefficiency effects model. On the basis of this literature this include in the technical inefficiency effects model socioeconomic, infrastructure and environmental degradation variables which have not traditionally been included as input variables in the production function. It is also cited in different literature that there are some important aspects that affect the technical inefficiency of Boro rice farms in the study area. In order to identify those factors, the inefficiency effect model uses the following variables which are shown in Table 2.

Table 2. Variables used in Estimation of the Inefficiency Effect Model.

\begin{tabular}{ll}
\hline Variables & Unit of Measurement \\
\hline Farm size & Area which is cultivated by a single Boro rice farmer (in bigha) \\
Household size & Number of family members \\
Age & Age of the farmer calculated in years \\
Education Level & formal education of the farmer measured in the years schooling \\
Experience & Length of growing Boro rice activity by the farmer measured in the number of years \\
Training & $1=$ if the farmer received any agricultural training, and 0 otherwise \\
Land fragmentation & Number of plots cultivated by the farmers \\
Extension service & $1=$ if the farmer get any extension service, and 0 otherwise \\
Credit opportunity & Amount of money taken by the farmer from different organizations \\
\hline
\end{tabular}


In this research ordinary least squares (OLS) also maximum likelihood estimates (MLE) method has been used to estimate the parameters of the stochastic production frontier. At present, there are a lot of software packages to estimate MLE parameters of the stochastic production function. In this study, computer software Frontier 4.1 has been used. However, it is significant to note that, technical efficiency model also inefficiency effect model has not been estimated step by step as discussed rather Frontier 4.1 software has been applied, which can estimate the coefficient of production function and inefficiency effect model altogether. Besides, data entry was made in computer and analyses were done using the concerned software SPSS v 21, MS Excel 2010 and MS Word 2010. The collected data were by hand edited and coded. Then all the collected data were summarized and scrutinized carefully. It may be noted here that information has been collected initially in local units. After necessary checking it has converted into standard international units.

\section{Results and Findings}

\subsection{Technical Efficiency Index of the Boro Rice Producing Farm in the Study Area}

The frequency distribution of the technical efficiency estimate from the stochastic frontier model is depicted in the Table 3 given below.

Table 3. Farm level technical efficiency index of Boro rice in the study area.

\begin{tabular}{lll}
\hline Efficiency interval & Numbers of Farms & Percent \\
\hline $0.500<\mathrm{TE}<0.600$ & 3 & 3 \\
$0.600<\mathrm{TE}<0.700$ & 6 & 6 \\
$0.700<\mathrm{TE}<0.800$ & 7 & 7 \\
$0.800<\mathrm{TE}<0.900$ & 11 & 11 \\
$0.900<\mathrm{TE}<1.00$ & 73 & 73 \\
Total & 100 & 100 \\
Minimum & 0.578 & \\
Maximum & 0.998 & \\
Average & 0.923 & \\
\hline
\end{tabular}

Source: Author's own calculation

The efficiency index in Table 3 shows that the efficiency level range varies from 0.00 to 1 . The average efficiency of rice farms is 0.923 which indicates that there is still room to increase efficiency in the production process. This implies that the production of the farm can be increased by $7.7 \%$ with the given technology without increasing the additional inputs. In the study area, about $73 \%$ of farms operate at an efficiency level between 0.90 and 1.00 . However, the average level of technical efficiency of farms shows that there is a certain level of technical inefficiency in the production of Boro rice in the study area. This result suggests that in the short term it is possible to increase the amount of Boro rice production in the study area by increasing the level of efficiency. Farmers can increase the efficiency level of their farms by controlling the use of production inputs that significantly contribute to influencing the level of production efficiency. To this end, it is essential to identify significant contributions from production that have a positive or negative contribution to production. In Section 5.2, significant production factors are estimated using the Cobb-Douglas production function. The table also shows that the minimum and maximum level of efficiency achieved by the sampling firms is 0.57 and 0.99 , respectively.

\subsection{Results of the Cobb-Douglas Production Frontier of Boro Rice}

The estimated results of OLS and MLE for Boro rice are presented simultaneously in Table 5.2. The first two columns show the variables of the production function and the corresponding parameters, respectively. The following columns show the estimated coefficients, std. error and tratios of MLE and OLS, respectively. The OLS estimates represent the average yield of producers. There are some factors such as the cost of the seed, the cost of the plow, the cost of pesticides, the cost of fertilizers, the cost of irrigation, etc. which affects the production of Boro rice in the study area.

The parameters of the Cobb-Douglas production function can be illustrated directly as the elasticity of input production in the production process. In Table 4 , it is found that the estimated coefficients of plowing cost, pesticide cost, labor cost and irrigation cost are statistically significant. This indicates that these factors of production are the main determinants influencing the production of Boro rice in the study area. The sign of the coefficients of all these variables is positive, except for the cost of labor and, therefore, has a negative effect on the production or efficiency of the Boro rice, shows a negative marginal productivity of labor in agriculture. On the other hand, the cost coefficients of the seed and the cost of the fertilizer are statistically insignificant. Therefore, the cost of seeds and the cost of fertilizers have no significant significance for influencing the production and technical efficiency of Boro rice.

The seed cost coefficient in the ML estimates is 0.0083 , which indicates that a $1 \%$ increase in seed cost can increase production by $0.0083 \%$ and is negligible. Similarly, the cost of the plow and the cost of the pesticide are 0.027 and 0.035 , respectively, which indicates that a $1 \%$ increase in the cost of the plow and the cost of the pesticide may increase the value of the production of Boro rice in $0.027 \%$ and $0.035 \%$, respectively. Also in this case, the fertilizer coefficient and the irrigation cost are 0.0035 and 1.002, which indicates that a $1 \%$ increase in fertilizer and irrigation costs can increase the value of the Boro rice production of $0.0035 \%$ and $1.002 \%$, respectively. 
Table 4. ML and OLS Estimates of the Stochastic Frontier Production Function Parameters for Boro Rice in Pabna District.

\begin{tabular}{|c|c|c|c|c|c|c|c|}
\hline \multicolumn{3}{|l|}{ ML Estimate } & \multicolumn{5}{|c|}{ OLS Estimate } \\
\hline Production Coefficient(In) & Unit & Coefficient & Std. Error & t-Statistic & Coefficient & Std. Error & t-Statistic \\
\hline Constant & $\beta_{0}$ & $1.813^{*}$ & 0.448 & 4.046 & $1.713^{*}$ & 0.429 & 3.99 \\
\hline Seed cost & $\beta_{1}$ & 0.0083 & 0.011 & 0.779 & 0.015 & 0.011 & 1.28 \\
\hline Ploug. cost & $\beta_{2}$ & $0.027 * * *$ & 0.136 & 1.907 & $0.031 * * *$ & 0.015 & 2.008 \\
\hline Pesticide cost & $\beta_{3}$ & $0.035^{*}$ & 0.009 & 3.627 & $0.033^{*}$ & 0.011 & 2.91 \\
\hline Fertilizer cost & $\beta_{4}$ & 0.0035 & 0.026 & 0.132 & 0.0003 & 0.022 & 0.013 \\
\hline Labor cost & $\beta_{5}$ & $-0.099 * *$ & 0.038 & -2.546 & $-0.079 * *$ & 0.034 & -2.31 \\
\hline $\begin{array}{l}\text { Irrigation cost } \\
\text { Inefficiency Effect Model }\end{array}$ & $\beta_{6}$ & $1.002 *$ & 0.026 & 37.54 & $0.987^{*}$ & 0.022 & 44.23 \\
\hline Constant & $\delta_{0}$ & 0.14 & 0.18 & 0.778 & & & \\
\hline Farm size & $\delta_{1}$ & $0.0315 * * *$ & 0.018 & 1.752 & & & \\
\hline Household size & $\delta_{2}$ & $-0.070 * * *$ & 0.039 & -1.79 & & & \\
\hline Age & $\delta_{3}$ & -0.0008 & 0.0009 & -0.861 & & & \\
\hline Education & $\delta_{4}$ & $-0.0281^{*}$ & 0.0095 & -2.96 & & & \\
\hline Experience & $\delta_{5}$ & $-0.016 * *$ & 0.007 & -2.41 & & & \\
\hline Training & $\delta_{6}$ & $0.956 * *$ & 0.407 & 2.35 & & & \\
\hline Land fragmentation & $\delta_{7}$ & -0.026 & 0.054 & -0.58 & & & \\
\hline Extension service & $\delta_{8}$ & 0.029 & 0.097 & 0.030 & & & \\
\hline Credit facility & $\delta_{9}$ & $-0.105^{*}$ & 0.030 & -3.514 & & & \\
\hline Sigma Squared & & $0.0012 *$ & 0.0004 & 3.145 & & & \\
\hline Gamma & & $0.822 * *$ & 0.397 & 2.072 & & & \\
\hline Log likelihood & 218.719 & & & & 211.35 & & \\
\hline LR test of one sided error & 14.72 & & & & & & \\
\hline
\end{tabular}

Source: Authors own calculation;

Note: $* * *, * * *$ indicates $1 \%, 5 \%$ and $10 \%$ level of significance

However, measuring production efficiency in agricultural production is an important issue from the point of view of agricultural development, as it provides relevant information useful for making sound management decisions, allocating resources and formulating agricultural policies and institutional improvements. The appropriateness of the stochastic frontier approach can be verified by calculating the value of the $\gamma$ parameter. If the value of $\gamma$ is close to zero, the deviations of the boundary are attributed to the noise, while a value close to the unit indicates that the deviation is attributed to the technical inefficiency. The results obtained revealed that the gamma value is 0.82 . This indicates that there is an $82 \%$ difference between the production of production edges observed and the maximum. The estimated value of $\gamma$ for the Boro rice producer is 0.822 . This means that about $82.2 \%$ of the discrepancies between the observed product and the frontier product is due to technical inefficiency. The coefficient of $\gamma$ in the result is significant at the $5 \%$ level suggests that the effect of technical inefficiency is significant and the presence of the unilateral

\subsection{Determinants of the Technical Inefficiency of the Production of Boro Rice}

In general, some socio-economic factors contribute to technical efficiency at farm level. Some of these have positive impacts and some have a negative impact on the level of technical efficiency of farmers. To address this problem, the variables considered include the size of the farm, the age of the farmer, the size of the family, the level of education, the agricultural experience, the fragmentation of the land, the formal training of the agricultural extension service, and the credit availability. The results of the inefficiency model in Table 4 show that the coefficients associated with family size, age, land fragmentation, education, experience and credit line are negative and statistically significant except for the age of respondent, the fragmentation of the earth and the extension service.

This indicates that the $1 \%$ increase in these variables can reduce the level of technical inefficiency of Boro rice production and thus increase technical efficiency. The farm size coefficient is positively correlated with technical inefficiency, which indicates that a $1 \%$ increase in firm size can reduce the level of technical efficiency. The coefficient associated with the fragmentation of the land is negative. This implies that more and more fragmentation of the land can reduce the level of inefficiency, but statistically insignificant. The coefficient associated with the credit line is negatively related to technical inefficiency and to the statistically significant $1 \%$ level to explain the inefficiency of the Boro rice producers. The sign of the age is negative, which indicates that an increase in the age of the farmer reduces technical inefficiency but conflicting. It is possible that the young farmer is more efficient and can use his work in the production of Boro rice, which increases agricultural productivity and decreases inefficiency. This result is similar to Hasnain M. Nehal et al. (2015), Alam et al. (2011), Obwona, (2006) and Al-Hassan (2012). The coefficient of experience is also statistically significant and negative, which means that farmers with agricultural experience are technically more efficient than farmers who have no experience. It can be seen in Table 4 that some of the variables influence the productive inefficiency of the company in an insignificant way. Therefore, further studies are needed to identify the unexplored explanation behind this 
result in the study area.

\subsection{Testing Hypotheses for the Production of Boro Rice}

In this study, the results of the least ordinary squares (OLS) and estimated maximum likelihood (MLE) for the Cobb-Douglas production function are shown in Table 4 that can be used to test the null hypothesis H0: $\gamma=0$, i.e., there is no technical efficiency in the production of rice. It should be noted that the values of log-likelihood function for the full stochastic frontier model and the OLS fit are calculated to be 218.719 and 211.35, respectively and reported in Table 4. This implies that the generalized likelihood ratio statistics to demonstrate the absence of technical ineffective effect of the frontiers is calculated as $\mathrm{LR}=-2 *(218.719-211.35)=14.72$, estimated from the Frontier 4.1 and reported as "LR" Test. of the one-sided error. The degrees of freedom for this test are calculated as $\mathrm{q}+1$, where $\mathrm{q}$ is the number of parameters other than $\gamma$ specified to be zero in $\mathrm{H}_{0}$, thus in our case $q=6$, Abedullah et al.(2007). The value of the "LR" test is significant because it exceeds the tabulated value taken by Kodde and Palm (1986). The test of the likelihood ratio of the logs indicates that there is no inefficiency in the data set and, therefore, the null hypothesis of lack of technical inefficiency in the production of rice is rejected. The hypothesis test of this study is based on the estimation of the gamma $(\gamma)$ in the frontier function to verify the existence of technical inefficiency in the model. The estimated $(\gamma)$ in the frontier model is positive, so the null hypothesis is not accepted and it can be concluded that the effect of technical inefficiency is present in the model.

\section{Conclusion and Recommendation}

The main objective of this study is to estimate the level of technical efficiency and determine the factors influencing technical inefficiency of Boro rice production using the Cobb-Douglas stochastic frontier approach. The study found that the Boro rice fields in the study area operate with less than total potential, since the average technical efficiency of farmers is $92.3 \%$. This implies that the production of the farm can be increased by $7.7 \%$ with the given technology without increasing the additional inputs. The results of the estimates clearly suggest that the size of the family, age, education, experience and credit line are the crucial factors that can reduce the technical inefficiency in the production of Boro rice. With reference to the results, the study suggests that the government should take the necessary measures to increase irrigation facilities, the level of education, training facilities and services to extend farmers, as well as improve the credit facilities of farmers. Therefore, in order to improve the productivity of long-term Boro rice, the production function must move upwards with the help of new production technologies. This implies that research institutes should focus on developing high-yielding and qualitative varieties, which has required more investment in research-related activities.

\section{References}

[1] Abedullah, Kouser, S. and Mustaq, K.(2007) Analysis of Technical Efficiency of Rice Production in Punjab (Pakistan), Pakistan Economic and Social Review, Vol. 45, No. 2 ( Winter 2007), pp.231-244

[2] Ahmadu, J. and Erhabor, P. O. (2012), Determinants of Technical Efficiency of Rice Farmers in Taraba State, Nigeria. Nigerian Journal of Agriculture, Food and Environment, 8(3), 2012, 78-84.

[3] Aigner, D. J., Lovell, K. C. A. and Schmidt, P. (1977) Formulation and Estimation of Stochastic Models. Journal of Econometrics, 6(---): pp 21-37.

[4] Bangladesh Bureau of Statistics (BBS), (2006). Statistical Yearbook of Bangladesh 2004. Dhaka: Statistics Division. Ministry of Planning, Government of the People's Republic of Bangladesh

[5] Bangladesh Bureau of Statistics (BBS), (2015). Yearbook of Agricultural Statistics of Bangladesh. Dhaka: Statistics Division, Ministry of Planning. Government of the People's Republic of Bangladesh.

[6] Bhuiyan, N. I., Paul, D. N. R., and Jabbar, M. A., (2002). Feeding the Extra Millions by 2025: Challenges for Rice Research and Extension in Bangladesh. A keynote paper presented at National Workshop on Rice Research and Extension-2002. Bangladesh, Gazipur, 29-31 January, 2002.

[7] Coelli, T., (1996a). A Guide to FRONTIER Version 4.1: A Computer Program for Stochastic Frontier Production and Cost Function Estimation. Centre for Efficiency and Productivity Analysis, University of New England, Armidale, NSW, 2351, CEPA Working Paper 96/07.

[8] Coelli, T., G. E. Battese,(1996), "Identification of Factors which Influence the Technical Inefficiency of Indian Farmers. Australian Journal of Agricultural Economics, 40, 103-128.

[9] Coelli, T. J.,(1995), "Recent Development in Frontier Modelling and Efficiency Measurement. Australian Journal of Agricultural Economics, 39(---): pp 219-245.

[10] [Coelli, T. J., Rahman, S. and Thirtle, C., (2002) "Technical, Allocative, Cost and Scale Efficiencies in Bangladesh Rice Cultivation: A Non-parametric Approach", Journal of Agricultural Economics", 2002, Vol.53, No.3, pp.607-626.

[11] Government of Bangladesh (2010). Bangladesh Economic Review, Economic Advisory Wings, Finance Division, Dhaka: Ministry of Finance, Dhaka.

[12] Hasan, M., Elias Hossain, Ataul Gani Osmani(2016). "Technical Efficiency of Boro Rice Production in Jhenaidah District of Bangladesh: A Stochastic Frontier Approach. International Journal of Agricultural Economics, Vol. 1, No. 4, 2016, pp. 103-107.

[13] Hasnain, M. N., Md. Elias Hossain, Md. Khairul Islam (2015). Technical Efficiency of Boro Rice Production in Meherpur District of Bangladesh: A Stochastic Frontier Approach. American Journal of Agriculture and Forestry, Vol. 3, No. 2, 2015, pp. 31-37. 
[14] Hossain, M. E., and Rahman, Z., (2012). Technical efficiency analysis of rice farmers in Naogaon district: An application of the stochastic frontier approach. Journal of Economics and Development Studies, 1(1), 1-20.

[15] Khan, A., Huda, A. F., and Alam, A.(2010). Farm household technical efficiency: A study on rice producers in selected areas of Jamalpur District in Bangladesh. European Journal of Social Sciences, 14(2), 262-271.

[16] Meeusen, W. and Van den Broeck, J.(1977) Efficiency Estimation from Cobb- Douglas Production Functions with Composed Error. International Economic Review, 18 (---): pp 435- 444.

[17] Nargis and Lee (2013) "Efficiency Analysis Of Boro Rice Production In North Central Region Of Bangladesh." The Journal of Animal \& Plant Sciences, 23(2): 2013, Page: 527533.

[18] Rahman, K. M. M. (2002). Measuring Efficiency of Producing Rice in Bangladesh: A Stochastic Frontier Analysis,
Wissenschaftsverlag Vauk Kiel KG in Germany, ISBN 38175-0357-1, pp. 1-215.

[19] Rahman, S. (2003) Profit Efficiency among Bangladeshi Rice Farmers. Food Policy 28(5-6): 487-504.

[20] Sharif, N. R. and Dar, A. A, (1996)“An Empirical Study of the Patterns and Sources of Technical Inefficiency in Traditional and HYV Rice Cultivation in Bangladesh," Journal of Development Studies, 1996, Vol. 32, No. 4, pp. 612 -629.

[21] Wadud, A. and B. White (2000). Farm household efficiency in Bangladesh: A comparison of stochastic frontier and DEA. Appl. Econ. 32: 1665-1673.

[22] Wadud, A., (2003) "Technical, Allocative, and Economic Efficiency of Farms in Bangladesh: A Stochastic Frontier and DEA Approach", The Journal of Developing Areas, 2003, Vol. 37, No. 1, pp. 109-126. 